\title{
Bronquiolite obliterante com pneumonia em organização*
}

\author{
Bronchiolitis obliterans organizing pneumonia \\ GABRIELA ADDOR, ANDREIA SALARINI MONTEIRO(TE SBPT), DAVID HENRIQUE NIGRI, WILHERMO TORRES, CARLOS \\ ALBERTO DE BARROS FRANCO(TE SBPT)
}

\begin{abstract}
Uma paciente 48 anos apresentou-se, assintomática, mas com achado radiológico de condensações alveolares, algumas constituindo nódulos em lobo superior direito, lobo médio e língula com predomínio perihilar. Foi considerado o diagnóstico diferencial de neoplasia, sarcoidose, doenças granulomatosas e tuberculose, entre outras doenças. 0 diagnóstico de bronquiolite obliterante com pneumonia em organização foi estabelecido através de videotoracoscopia e foi iniciado o tratamento com esteróides. Houve boa evolução com resolução radiológica.
\end{abstract}

J Bras Pneumol 2004; 30(2) 154-157

Descitores: Bronquiolite obliterante. Bronquiolite obliterante com pneumonia em organização
48 years-old woman, asymptomatic, presented with radiographic findings of patchy airspace consolidation with nodular opacities in the upper right lobe, middle lobe and lingula. The differential diagnoses of neoplasms, sarcoidosis, granulomatous diseases and tuberculosis were considered. Diagnosis of Bronchiolitis obliterans organizing pneumonia was made by means of videothoracoscopy whereupon treatment with corticosteroids was begun. The patient had a positive evolution with resolution of the radiographic finding.

Key words: bronchiolitis obliterans organizing pneumonia, bronchiolitis obliterans

alvéolos, e com o freqüente acometimento também de bronquíolos ${ }^{(1,7)}$. Esse padrão histopatológico pode estar associado a doenças do tecido conjuntivo, vasculites, infecções, pneumonite de hipersensibilidade, pneumonia obstrutiva, aspiração, uso de drogas, toxinas sistêmicas ou inaladas, pneumonia eosinofílica crônica, malignidades hematológicas, ou também ser de doença idiopática ${ }^{(7,8)}$. Neste último caso, é preferencialmente chamada pneumonia criptogênica em organização (COP). Como a utilizacão do termo B00P pode causar confusão com outras doenças de vias aéreas como a bronquiolite constritiva(1), e enfatiza

\footnotetext{
* Trabalho realizado na Escola Médica de Pós-Graduação da PUC-RJ. Disciplina de Pneumologia e na Clínica Narros Franco-Consultoria em Aparelho Respiratório

Endereço para correspondência - Gabriela Addor. Rua Sorocaba 464/402, Botafogo, Rio de Janeiro/RJ

CEP: 22271-110. Tel: 22667392.e-mail: gaddor@globo.com / respirar@pobox.com

Recebido para publicação, em 8/5/3. Aprovado, após revisão em, 26/8/3.
} 
demasiadamente o componente bronquiolar, que pode ser encontrado em outras afecções não associadas a pneumonia em organização, ele tem sido cada vez menos empregado ${ }^{(3)}$. 0 uso do termo genérico pneumonia em organização foi portanto proposto, com as modificações adequadas a cada caso, como por exemplo: pneumonia em organização associada a artrite reumatóide, pneumonia em organização associada a pneumonia viral, etc ${ }^{(1)}$.

\section{RELATO DO CASO}

Uma engenheira, de 48 anos, tabagista (25 anos/maço), assintomática, foi submetida a exame radiológico de tórax de rotina, que evidenciou infiltrado alveolar em lobo superior direito e lobo médio. Não havia história de infecção recente, uso de drogas sistêmicas ou inaladas, ou de viagem recente. Negava história de asma ou sinusopatia.

0 exame físico era normal. A tomografia computadorizada de alta resolução do tórax mostrou condensações alveolares, algumas constituindo nódulos, em lobo superior direito, lobo médio e língula, com predomínio perihilar (Figuras 1 e 2). A espirometria foi normal, com volume expiratório forçado no primeiro segundo $\left(V F_{1}\right)$ de 2.58L (91\%) e capacidade vital lenta (CV) de 3.68L (107\%). 0 teste de caminhada de seis minutos não apresentou alterações, com saturação inicial de 0 , de $98 \%$ e final de $97 \%$, sendo a distância percorrida de 320 metros. A sorologia para HIV foi negativa. Hemograma, VHS, proteína $\mathrm{C}$ reativa e cálcio sérico eram normais. As sorologias para doenças do colágeno e vasculites sistêmicas (incluindo FAN, ANCA , AntiDNA, Anti-Sm, Anti-SS-A, Anti-SS-B e fator reumatóide) foram negativas. A broncofibroscopia com biópsia transbrônquica foi normal, com exame bacterioscópico pela coloração de Gram, cultura para germes comuns, BAAR, pesquisa direta para fungos e PCR para Mycobacterium tuberculosis negativos no lavado broncoalveolar. 0 exame histopatológico resultou inconclusivo. Foi realizada biópsia pulmonar por videotoracoscopia, a qual foi compatível com BOOP (Figura 3). Foi então iniciada prednisona a $40 \mathrm{mg} / \mathrm{dia}$, com melhora tomográfica importante em 45 dias. Após seis meses havia somente discreto infiltrado em vidro fosco.
Siglas e abreviaturas utilizadas neste trabalho:

BOOP: Bronquiolite obliterante com pneumonia em organização

TCAR: tomografia computadorizada de alta resolução BAAR: bacilo álcool-ácido resistente

COP: pneumonia criptôgenica em organização

PCR: reação em cadeia da polimerase (polimerase chain reaction)

FAN: anticorpo antinuclear

ANCA: anticorpo anti citoplasma de neutrófilos

\section{DISCUSSÃO}

A B00P idiopática é a forma mais comum de B00P e geralmente surge entre a quinta e a sexta décadas de vida, mais freqüentemente em não tabagistas, sem predileção entre os sexos. Sua incidência e prevalência ainda não foram
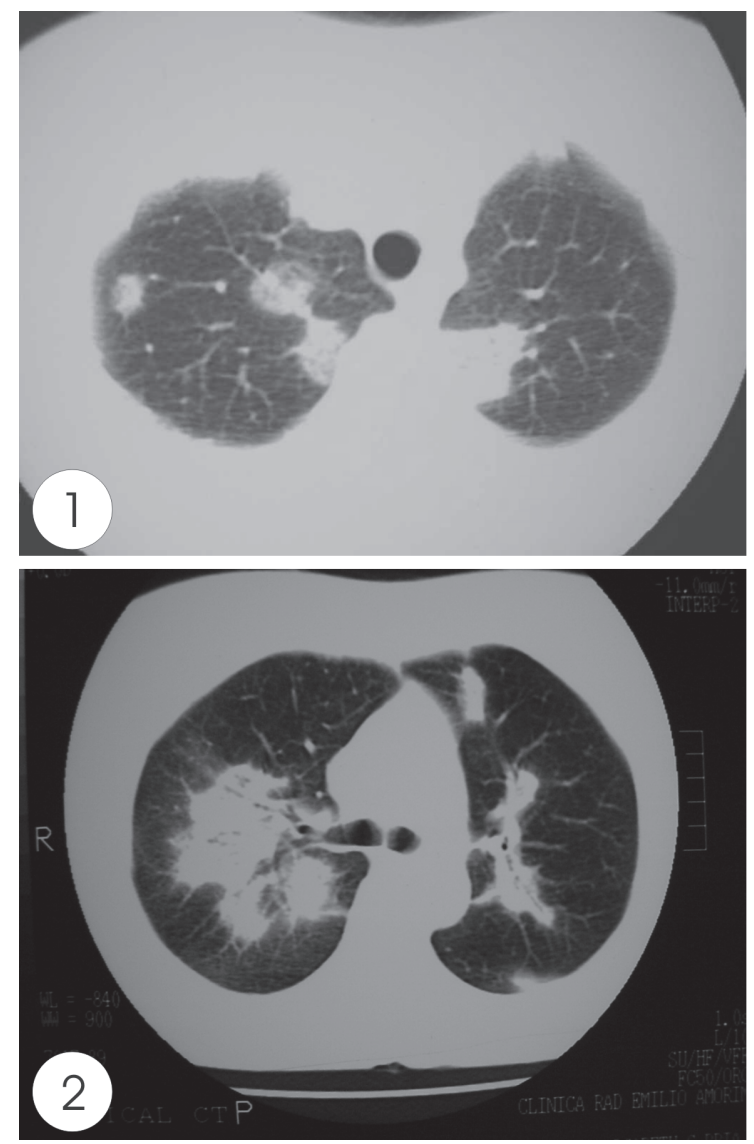

Figuras 1 e 2. Áreas de consolidação alveolar com broncograma aéreo, algumas assumindo aspecto de nódulos, mais confluentes em região perihilar direita. 
estabelecidas $^{(1)}$. A sintomatologia é geralmente inespecífica, e pode estar ausente em 13\% dos $\operatorname{casos}^{(6)}$, como ocorreu nesta paciente, que procurou atendimento pneumológico por apresentar alterações no radiograma de tórax. Os pacientes geralmente apresentam tosse e dispnéia, podendo também ocorrer sintomas constitucionais, como perda de peso, mialgia, mal estar, prostração e febre. Nos exames laboratoriais pode haver aumento do VHS e da proteína $\mathrm{C}$ reativa ${ }^{(7)}$. Os achados clínicos mais comuns são estertores crepitantes e taquipnéia. Baqueteamento digital normalmente está ausente. Os achados radiológicos mais comuns são áreas de consolidação uni ou bilateralmente. Pequenas opacidades nodulares podem ser encontradas em $10 \%$ a $50 \%$ dos casos. À tomografia do tórax observa-se consolidação do espaço aéreo em 90\% dos casos de BOOP, com predomínio em áreas inferiores. A atenuação em vidro fosco pode ser encontrada em $60 \%$ dos $\operatorname{casos}^{(1)}$. Em 15\% dos pacientes pode-se encontrar múltiplos nódulos ${ }^{(1)}$.

Contrariamente aos achados mais comuns da literatura, a paciente deste caso era assintomática e o exame radiológico não usual (infiltrado com nódulos predominando nos lobos superiores), o que levou à pesquisa dos seguintes diagnósticos diferenciais: sarcoidose, neoplasias, doença fúngica, proteinose alveolar, granulonatose de Wegener e tuberculose.

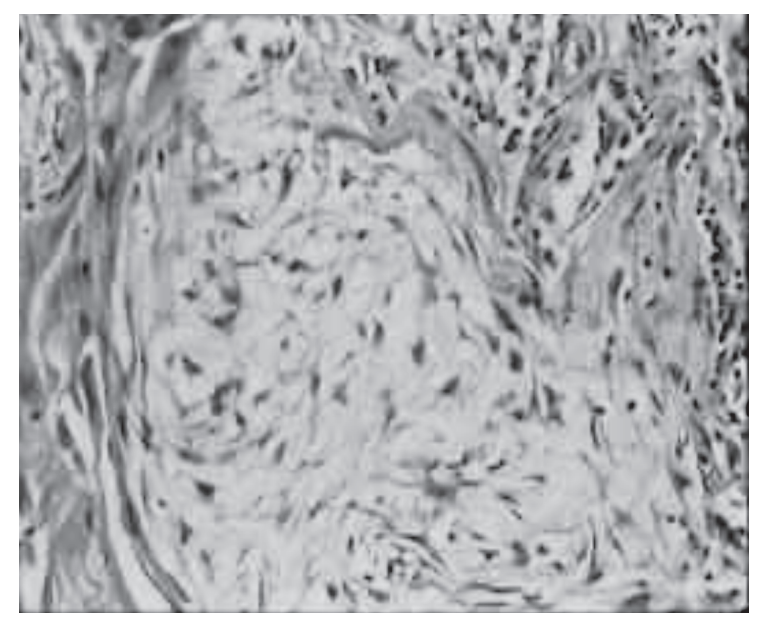

Figura 3. Proliferação fibroblástica jovem, com alguma concentricidade, ocupando a luz alveolar(HE 400x)
Para o diagnóstico de B00P é necessária a coleta de material para o exame histopatológico, a qual pode ser realizada através de biópsia transbrônquica, que apesar de demostrar bronquiolite obliterante na maioria dos casos, não é adequada na exclusão de lesões associadas. Isso não ocorre na biópsia cirúrgica, pois o material é obtido sob visão direta e em maior quantidade. 0 papel da biópsia transbrônquica no diagnóstico da B00P ainda não está totalmente definido ${ }^{(1)}$. A paciente foi submetida à biópsia transbrônquica, que foi inconclusiva pois no material obtido não havia componente representativo pulmonar. A biópsia pulmonar por videotoracoscopia neste caso foi essencial para a definição diagnóstica. Não houve complicação relacionada ao procedimento.

0 diagnóstico de COP é feito através da exclusão de outra patologia ou mecanismo agressor associado ao quadro de B00P. No presente caso, as sorologias para colagenose e vasculites sistêmicas foram negativas e a biópsia cirúrgica foi importante na exclusão de doenças infecciosas ou neoplásicas que poderiam estar associadas.

A maioria dos pacientes tem recuperação completa com a administração de corticóide, prednisona em doses que variam de $0.75 \mathrm{mg} / \mathrm{Kg}$ a $1,5 \mathrm{mg} / \mathrm{kg}$ como dose inicial, a qual deve ser mantida por seis a doze meses, e posteriormente reduzida gradualmente ${ }^{(7)}$. Um pequeno percentual de pacientes recupera-se espontaneamente ${ }^{(7)}$. Raramente ocorre progressão para insuficiência respiratória e óbito. A evolução para fibrose intersticial difusa sugere outro diagnostico, assim como a recaída com doses de esteróide superiores a $20 \mathrm{mg}^{(8)}$. Pode ocorrer recidiva após a redução ou retirada do corticóide, geralmente no primeiro ano após o diagnóstico, em 9\% a 58\% dos casos ${ }^{(8)}$, porém não há relação entre o número de recidivas e o prognóstico ${ }^{(7,8)}$. Por ser a B00P uma doença de característica benigna, raramente evoluindo com insuficiência respiratória e óbito, é importante o estabelecimento de um protocolo de tratamento equilibrado e eficiente com mínimos efeitos colaterais. Não existe um consenso na literatura sobre a oportunidade de tratamento e a dose a ser utilizada de corticosteróides. 0 tratamento precoce parece evitar recidivas ${ }^{(8)}$. Neste caso clínico optou-se pela utilização de doses menores de prednisona $(0.75 \mathrm{mg} / \mathrm{kg})$, com redução gradual e 
suspensão em seis meses. Observou-se boa resposta radiológica e ausência de recidiva até o momento. A boa resposta também pode ser atribuida ao início do tratamento numa fase assintomática.

No presente caso, a paciente apresentava achado radiológico extenso sem associação com alterações clínicas ou laboratoriais, e a biópsia pulmonar cirúrgica foi o único método capaz de estabelecer o diagnóstico. A instituição de tratamento na fase assintomática, associada a uma dose mais baixa de corticosteróide com posterior redução gradual, mostrou boa resposta, sem efeitos colaterais graves ou recidivas.

\section{REFERÊNCIAS}

1. Joint statment of ATS and ERS. Classification of the idiopatic interstitial pneumonias; internacional consensus statement. Am J Respir Crit Care Med 2002;165:277-304.

2. Mokhtari M, Bach PB, Tietjen PA, Stover DE. Bronchiolitis obliterans organizing pneumonia in cancer: a case series. Respir Med 2002;96:280-6.
3. Fortuna FP, et al. 0 espectro clínico e radiológico da pneumonia em organização: análise retrospectiva de 38 casos. J Pneumol 2002;28(6):317-32.

4. De Almeida $P$, et al. Bronquiolite obliterante na forma nodular. J Pneumol 2002;28:335-8.

5. Kroegel C, Reibetaig A, Hengst U, Mock B, Hafner D, Grahmann PR. Bilateral symmetrical upper-lobe opacities: an unusual presentation of bronchiolitis obliterans organizing penumonia. Chest 2000;118:863-5.

6. Cazzoto S, et al. Bronchiolitis obliterans-organizing pneumonia: an Italian experience. Respir Med ; 94:702-08.

7. Cordier JF. Organising pneumonia. Thorax 2000;55:31828.

8. Lazoir R, et al. Cryptogenic organizing pneumonia: characteristics of relapses in a series of 48 patients. Am J Crit Care Med 2000;162:571-7.

9. Kuru T. Nonresolving or slowly resolving pneumonia. Clin Chest Med 1999;20:623-51.

10. Fishman AP. Chronic obstructive lung disease: overview. In: Fishman AP, editor. Fishman's pulmonary diseases and disorders. 3rd ed. New York: McGraw-Hill; 1998. Chap.42, p.645-58.

11.King TE. Bronchiolitis. In: Fishman AP, editor. In: Fishman's pulmonary diseases and disorders. 3rd ed. New York: McGraw-Hill; 1998. Chap.54, p.825-47. 